\title{
Short Note \\ MORPHOLOGICAL CHARACTERIZATION OF CAULIFLOWER VARIETIES/CULTIVARS USING DUS CHARACTERS
}

\author{
B. Singh ${ }^{* 1}$, T. Chaubey, Aastik Jha, D.K. Upadhyay and S.D. Pandey \\ Indian Institute of Vegetable Research, Varanasi-221305 (Uttar Pradesh), India
}

Cauliflower is a cool season crop; it is more exacting in its climatic requirements than most other crops in this family. The plant is extremely sensitive to unfavourable conditions, such as unusually hot weather, drought or too low temperature, which often result in the formation of premature curds. It is monogenomic species whose genomic constitution is $\mathrm{C}$ and chromosome number is $\mathrm{n}=9$ belongs to Cruciferae family (Thamburaj and Singh, 2001). The variety attains acceptance when the farmers get genetically pure seed of high standard. For the purpose, each cultivar should be properly defined with suitable descriptors, so as to maintain its identity during seed production through field inspection and certification. In India, Protection of Plant Varieties and Farmer's Right Act, 2001 (PPVandFRA, 2001) envisages the registration and protection of new and notified/extant plant varieties based on the criteria of Distinctness, Uniformity and Stability (DUS) of morphological characteristics and increasing attention is being paid towards comprehensive plant genetic recourses.

The characterizations of 15 varieties were done to use as reference material for protection of other varieties under PPVand FR Rules, 2003. Therefore, the database of cauliflower varieties generated may be useful for the selection of suitable varieties to be compared against the candidate varieties developed in India as and when required. This investigation may also be helpful to the researchers with respect to breeding of cauliflower varieties for particular traits. Moreover, farmers can also get benefit with regards to selection of suitable varieties of their interest.

The present investigation was carried out for successive three years during Rabi season of 2010 to 2012 to carry out characterization of already released cauliflower varieties at Research Farm, Indian Institute of Vegetable Research, Varanasi, India. The seed materials for the present investigation comprised of 15 varieties i.e Pusa Paushja, Pusa Sharad, Pusa Himjyoti, Pusa Shukti, Pusa Meghna, Pusa Deepali, Kashi Kunwari, Kashi Agahani, CCS-80, Pant Gobhi-3, Pusa Subhra,

\footnotetext{
${ }^{*}$ Corresponding author:bsinghiivr@gmail.com

${ }^{1}$ Project Coordinator (All India Coordinated Research Project on Vegetable Crops)
}

Received: 30.07.2013 
Pusa Snow Ball-1 PSBK-1, PSB-16 and PSBK-25. The field experiment was laid out in a randomized block design with three replications. Each plot consisted of four rows of $5 \mathrm{~m}$ length with spacing of $50 \mathrm{~cm}$ between rows and $50 \mathrm{~cm}$ between plants and all the recommended agronomic practices were followed to raise the good crop. The observations were recorded on 10 plants in each replication at specific stages of crop growth period when the characters under study had full expression. Varieties were evaluated for 28 DUS qualitative and quantitative characters listed in National DUS test guidelines descriptors for cauliflower viz; seedling: anthocyanin colouration of hypocotyl, outer stem (stalk): length (up to insertion of first leaf), leaf attributes viz; leaf: attitude, length, width, shape, lobe, colour, waxiness, torsion of tip profile of upper side of blade, puckering, crimping near main vein and degree of undulation of margin, curd characteristics viz; curd: initiation (days to 50\% of the plants with curd initiation from sowing of seed), covering by inner leaves, polar diameter, equatorial diameter, shape in longitudinal section, doming, colour, knobbing, texture, compactness, anthocyanin colouration at maturity, maturity group, flower: colour, and stalk length (Anonymous, 2009).

The characterization of cauliflower varieties is presented in table- 1 and frequency distribution of each descriptor of released varieties along with example varieties is depicted in table- 2 .

The varieties were classified on the basis of seedling anthocynin pgiment of hypocotyls into two groups i.e. absent and present. Most of the varieties exhibited absent while, snowball group (Pusa Snowball-1, PSBK-1, PSB-16) expressed seedling anthocyanin colouration. Based on outer stem (stalk) length, cauliflower varieties were grouped as short, medium and long. Two varieties namely Pusa Sharad and Pusa Snow Ball-1 expressed medium and 13 varieties showed long stalk length while, none of the varieties depicted short outer stem (stalk) length. As per leaf attitude, three varieties i.e. Pusa Himjyoti, Pusa Snow Ball-1 and PSBK-25 expressed erect while, Pusa Meghna and Kashi Aghrahani showed horizontal and rest 10 varieties showed semi erect type. Leaf length of cauliflower varieties classified into three categories viz; short, medium and long. However, in the present study, only four varieties i.e. Pusa Meghna, Pusa Shukti, PSB-16 and Pusa Sharad had short leaf length, ten varieties showed medium leaf length and other varieties showed long leaf length. Considerable variation was also observed for leaf shape, variety like Pusa Meghna was of narrow elliptic leaf shape while, Pusa Paushja, Pusa Sharad, PSB-1, Pusa Himjyoti, Pant Gobhi-3, PSBK-25, Pusa Deepali and Kashi Agahani were of elliptic type and rest varieties i.e. Pusa Snow Ball K-1, Pusa Shukti, CCH-80, Pusa Subhra, PSB-16 and Kashi Kunwari had broad elliptic type leaf shape. On the basis of leaf lobe, the varieties were classified in two group viz; absent and present. Most of the varieties expressed leaf lobe except Pusa Paushja, Pusa Sharad, Pusa Himjyoti, Pusa Snow Ball-1and Pusa Shukti. 
The varieties were also classified on the basis of leaf colour in three groups i.e. light green, dark green and bluish. Most of the varieties were found to have light and dark green leaves except Pusa Paushja which showed as bluish leaf colour. Leaf waxiness was another trait with good variability. On the basis of this character, the varieties were categorized into four groups i.e. absent, light, medium and strong. Waxiness was absent in Pusa Meghna while, Pusa Paushja, CCS-80, Pant Gobhi-3, Pusa Subhra and PSB-16 exhibited medium waxiness. Varieties like Pusa Himjyoti, Pusa Snow Ball-1, Pusa Shukti, PSBK-1 and Pusa Meghna expressed light whereas; Pusa Paushja and PSBK-25 showed strong leaf waxiness. The trait leaf torsion of tip was categorized into four categories namely, absent, weak, medium and strong. Five varieties i.e. Pusa Snow Ball-1, Pusa Shukti, Pusa Meghna, Pusa Deepali and Kashi Kunwari depicted absent, while, 5 varieties expressed weak and rest varieties showed medium torsion of leaf tip. None of the varieties showed strong torsion of leaf tip. On the basis of leaf profile of upper side of blade character, the varieties were classified into three groups i.e. concave, flat and convex. Varieties like, Pusa Snow Ball-1, Pusa Shukti, Pusa Deepali, Kashi Kunwari and Kashi Agahani were of flat type leaf while, Pusa Paushja, Pusa Sharad, Pusa Himjyoti, CCS-80, Pant Gobhi-3 and PSBK-1 showed convex and rest varieties showed concave type leaf. Among the varieties, weak leaf puckering was absent in Pusa Himjyoti, Pusa Snow Ball-1, Pusa Meghna and Kashi Kunwari whereas, Pusa Paushja, Pusa Sharad, CCS-80, Pant Gobhi-3, Pusa Subhra, PSBK-1 and Kashi Agahani expressed medium and Pusa Shukti, PSBK-25 and Pusa Deepali showed strong leaf puckering characters. In the favour of leaf crimping near main vine, the varieties have been grouped into four categories, viz; seven varieties as weak, five as medium and 3 as strong whereas, none of the varieties had no leaf crimping near main vine. On the basis of curd initiation, cauliflower varieties can be classified into three categories viz; early ( $<75$ days), medium (75-100 days), late ( $>100$ days). There are three varieties with early curd initiation e.g. Pusa Meghna, Pusa Deepali and Kashi Kunwari while, 9 varieties i.e. Pusa Himjyoti, Kashi Agahani, Pusa Paushja, Pusa Sharad, Pusa Shukti, CCS-80, Pant Gobhi-3 and Pusa Subhra were in medium group and Pusa Snowball -1, PSBK1, PSB-16 and PSBK-25 exhibited late curd initiations. Curd covering by inner leaves was another trait with good variability. On the basis of this character, the varieties were grouped into three types viz; not covered, partly covered, and covered. Four varieties (Kashi Kunwari, Pusa Himjyoti, Pusa Deepali and Pusa Meghna) were not covered, whereas, Kashi Agahani Pusa Paushja, Pusa Sharad, Pusa Shukti, CCS80, Pant Gobhi-3 and Pusa Subhra exhibited partly covered and four (PSBK-1, PSB-16, PSBK-25 and Pusa Snow Ball-1) varieties covered by inner leaves. Based on polar diameter of curd, varieties were classified into 3 groups viz; small $(<15 \mathrm{~cm})$, medium $(15-20 \mathrm{~cm})$ and large $(>20 \mathrm{~cm})$. Proportionate distributions of varieties in small and medium group were observed. Only two varieties Pusa Shukti and PSBK-1 were in large group. Equatorial diameter of curd cauliflower varieties were grouped as small, medium and large, accordingly, 4 varieties as small, 9 as medium and 2 
were observed as large equatorial diameter during experimentation. Dubey et al., (2003) reported high variability in curd size of cauliflower. Shape in longitudinal section of curd is another character with sufficient variability in cauliflower varieties. Circular shape was observed in Pusa Himjyoti, broad elliptic was observed in 11 varieties viz; Kashi Kunwari, Kashi Agahani, Pusa Paushja, Pusa Sharad, Pusa Shukti, CCS-80, Pant Gobhi-3, Pusa Subhra, PSBK-1, PSB-16 and PSBK-25, while, Pusa Snow Ball-1, Pusa Megna and Pusa Deepali were depicted as narrow elliptic. The character of curd doming was categorized as weak, medium and strong. In this respect variety Pusa Meghna showed weak and variety Pusa Paushja expressed have strong curd doming whereas, rest of other varieties were depicted as medium curd doming. Curd colour varied from white to creamy white in the varieties studied. Pusa Paushja, Pusa Sharad, PSBK-1 and PSBK-25 exhibited white colour whereas, rest of the varieties showed creamy white colour. Curd knobbing is important character categorized into three categories i.e. fine, medium and course. Most of the varieties showed medium knobbing except PSBK-1 which expressed fine curd knobbing. Among the 15 cauliflower varieties studied considerable variation was observed for all the characters except curd texture (Table-1) where all the varieties exhibited fine curd texture. On the basis of curd compactness, the varieties were classified into three groups viz; loose, medium and compact, seven varieties were found as medium type and 8 varieties of compact type. Similar findings were reported by Singh et al., (2005). Kumar et al. (2010) found significant differences among the genotypes in Indian cauliflower suggesting sufficient variability for yield and quality characters.

The trait anthocyanin colouration of curd at maturity was categorized into two categories namely, absent and present. Two varieties depicted as present and rest of 13 varieties showed absent in anthocyanin curd colouration. Curd maturity group is most important character which classified as early, mid early, mid late and late. Only one variety Pusa Deepali was found early, whereas, Kashi Kunwari, Pusa Meghna was expressed as mid early group, Pusa Paushja, Pusa Sharad, Pusa Himjyoti, Pusa Shukti, CCS-80, Pant Gobhi-3 and Pusa Subhra were exhibited as mid late group and all the snow ball group varieties were depicted as late group for maturity. Late group varieties viz; Pusa Snow Ball-1, PSB-16, PSBK-1, PSB-16 and PSBK-25 could not flower due to lack of chilling requirement in northern plane in India. Flower colour grouped as white, creamy white and yellow. Among the 11 flowered varieties, three varieties namely Pusa Himjyoti, Pusa Deepali and Pusa Meghna expressed creamy white, and rest of the other varieties showed yellow flower colour while, none of the variety was depicted as white colour. Similar grouping trends were reported by Singh et al., (2012) in cabbage. The trait flower stalk length was categorized into three categories namely short, medium and long. Out of these, two varieties was depicted as short stalk length and 9 varieties showed medium stalk length.

It is concluded that the DUS descriptors can be effectively used for identification and grouping of varieties and satisfying the DUS criteria for these morphological descriptors could be registered under PPV and FR Act. Pre-breeding 
or genetic enhancement needs emphasis for transfer or introgression of genes and gene combinations from unadapted source into more usable breeding material. There are indications that novel and useful traits can be successfully combined from related varieties. Further, these varieties can be used in varietal improvement programme depending upon the desired characteristics. However, registration of candidate varieties only considered under DUS testing as per the legal frame work and till now, morphological characterizations are being considered as per PPV and FR Act for notified vegetable crops.

\section{ACKNOWLEDGEMENTS}

The authors gratefully acknowledge the PPV\&FR Authority, New Delhi for financially support, assistance through PVP legislation and DUS testing project.

\section{REFERENCES}

Anonymous. 2009. PPV and FR Authority specific DUS test guidelines for nine crop species - Brassica oleracea (Botrytis L.). Plant Variety Journal of India, 3 (11):217-229

Dubey, R.K., Singh, B.P. and Ram, H.H. 2003. Genetic variability, heritability and genetic advance for quantitative characters in Indian cauliflower (Brassica Oleracia var. Botrytis L.). Vegetable Science, 30(1): 81-82

Kumar, M. Mahesh, S.R. Sharma, Kalia, P. and Saha, P. 2010. Genetic variability and character association for quantitative and quality traits in early maturing Indian cauliflowers. Indian Journal of Horticulture, 67:218-223

PPV and FR, 2001. Protection of Plant Varieties and Farmer's Right Act (No. 53 of 2001) Dept. of Agriculture and Cooperation, Ministry of Agriculture, Govt of India, Krishi Bhavan, New Delhi

Singh, B., Chaubey, T., Upadhyay, D.K., Jha, A. and Pandey, S.D. 2012. Morphological characterization for DUS testing of cabbage (Brassica oleracea var. capitata L.) genotypes. Progressive Horticulture, 44 (1): 170-173

Singh, B., Singh, A.K., Pandey, S and Rai, M. 2005. Effect of curd cutting techniques at different curd stage on seed production in Indian cauliflower (Brassica Oleracia var. Botrytis L.). Vegetable Science, 32(1): 80-81

Tamburaj, T. And Singh, N. 2001. Textbook of Vegetables, Tuber crops and Spices, ICAR (Pub.) New Delhi 
Table 1: Description of morphological DUS descriptors for fifteen cauliflower varieties/ cultivars.

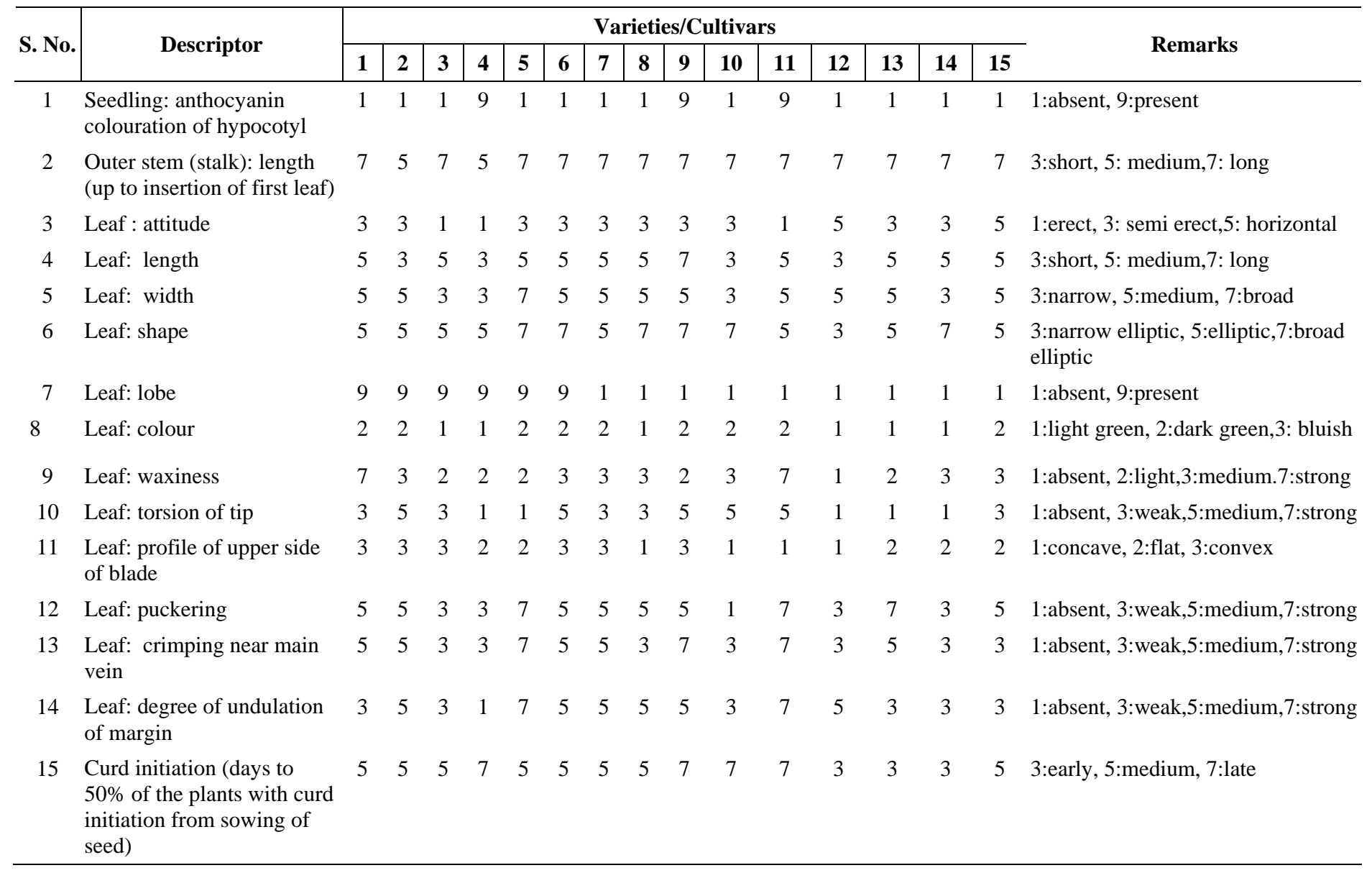




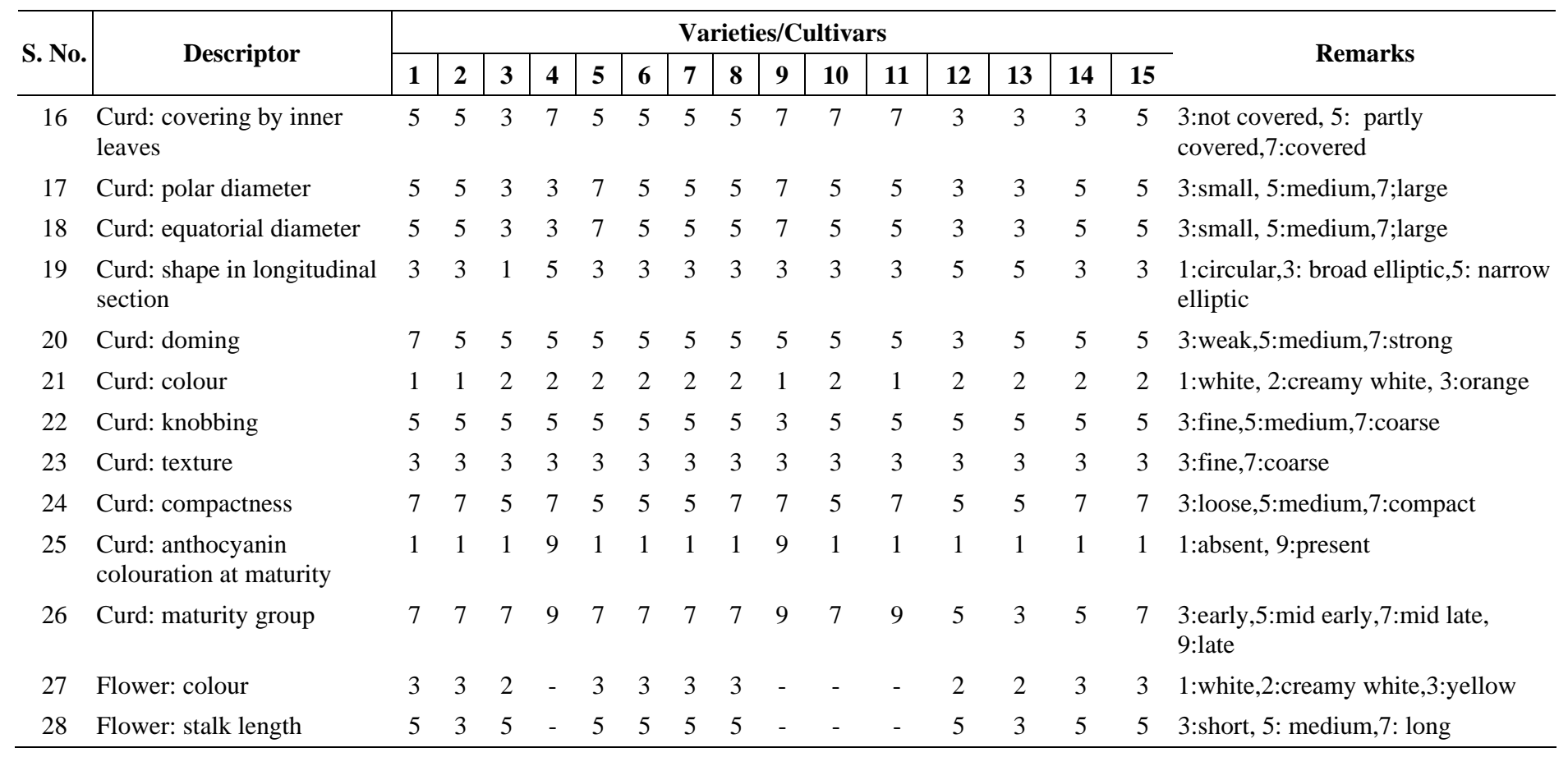

Varieties/cultivars: 1: Pusa Paushja, 2: Pusa Sharad, 3: Pusa Himjyoti,4: Pusa Snow Ball-1, 5: Pusa Shukti,6: CCS-80, 7: Pant Gobhi-3, 8: Pusa Subhra,9: PSBK-1,10: PSB-16, 11:PSBK-25,12: Pusa Meghna,13: Pusa Deepali, 14: Kashi Kunwari, 15: Kashi Agahani

Note: (-) is Pusa Snow Ball-1, PSBK-1, PSB-16 and PSBK-25 are snowball group. Temperate region is suitable for this group flowering. 
Table 2: Frequency distribution and example varieties of some important attributes of 15 varieties/ cultivars of cauliflower

\begin{tabular}{|c|c|c|c|}
\hline Plant descriptors & \begin{tabular}{|c|c|}
$\begin{array}{c}\text { Range in } \\
\text { expression }\end{array}$ \\
\end{tabular} & \begin{tabular}{|c|} 
No. of \\
varieties
\end{tabular} & Example varieties \\
\hline \multirow{2}{*}{$\begin{array}{l}\text { Seedling: anthocyanin } \\
\text { colouration of hypocotyl }\end{array}$} & absent & 12 & Pusa Deepali, Kashi Agahani \\
\hline & present & 3 & PSBK-1, PSBK-25, Pusa Snowball-1 \\
\hline \multirow[t]{3}{*}{ Leaf : attitude } & erect & 3 & PSBK-25, Pusa Snowball-1 \\
\hline & semi-erect & 10 & $\begin{array}{l}\text { Pusa Paushja, Pusa Sharad, Pusa } \\
\text { Himjyoti }\end{array}$ \\
\hline & horizontal & 2 & Pusa Meghna \\
\hline \multirow[t]{3}{*}{ Leaf: length } & short $(<35 \mathrm{~cm})$ & 4 & Pusa Meghna, Pusa Shukti, PSB-16 \\
\hline & medium $(35-50 \mathrm{~cm})$ & 10 & Pusa Sharad, Kashi Agahani, CCS-80 \\
\hline & large $(>50 \mathrm{~cm})$ & 1 & PSBK-1 \\
\hline \multirow[t]{3}{*}{ Leaf: width } & narrow ( <15 cm) & 4 & Pusa Himjyoti, Kashi Kunwari \\
\hline & medium ( $15-25 \mathrm{~cm})$ & 10 & Kashi Agahani, Pusa Deepali, , PSBK-25 \\
\hline & broad $(>25 \mathrm{~cm})$ & 1 & Pusa Shukti \\
\hline \multirow[t]{3}{*}{ Leaf: shape } & narrow elliptic & 1 & Pusa Meghna \\
\hline & elliptic & 8 & $\begin{array}{l}\text { Pusa Paushja, Pusa Sharad, PSB-1, Pusa } \\
\text { Himjyoti }\end{array}$ \\
\hline & broad elliptic & 6 & Pusa Snow Ball-1, Pusa Shukti \\
\hline \multirow{3}{*}{$\begin{array}{l}\text { Leaf: profile of upper } \\
\text { side of blade }\end{array}$} & concave & 4 & Pusa Meghna, PSB-16 \\
\hline & flat & 5 & Pusa Shukti, Kashi Kunwari, Pusa Deepali \\
\hline & convex & 6 & Pusa Paushja, Pusa Sharad, Pusa Himjyoti \\
\hline \multirow[t]{4}{*}{ Leaf: puckering } & absent & 1 & PSB-16 \\
\hline & weak & 4 & $\begin{array}{l}\text { Kashi Kunwari, Pusa Meghna, Pusa } \\
\text { Himjyoti }\end{array}$ \\
\hline & medium & 7 & Kashi Agahani Pusa Paushja, Pusa Sharad, \\
\hline & strong & 3 & Pusa Deepali, Pusa Shukti \\
\hline \multirow{4}{*}{$\begin{array}{l}\text { Leaf: crimping near } \\
\text { main vein }\end{array}$} & absent & 0 & Nil \\
\hline & weak & 7 & Kashi Kunwari, Pusa Meghna \\
\hline & medium & 5 & Pusa Paushja, Pusa Sharad, Pusa Deepali \\
\hline & strong & 3 & Pusa Shukti, PSBK-25, PSBK-1 \\
\hline \multirow{3}{*}{$\begin{array}{l}\text { Curd initiation (days to } \\
50 \% \text { of the plants with } \\
\text { curd initiation from } \\
\text { sowing of seed) }\end{array}$} & early (<75 days) & 2 & Pusa Meghna, Pusa Deepali \\
\hline & medium (75-100) & 9 & $\begin{array}{l}\text { Kashi Kunwari, , Pusa Himjyoti, Kashi } \\
\text { Agahani Pusa Paushja, Pusa Sharad, Pusa } \\
\text { Shukti }\end{array}$ \\
\hline & late $(>100)$ & 4 & $\begin{array}{l}\text { Pusa Snowball -1, PSBK-1, PSB-16, } \\
\text { PSBK-25 }\end{array}$ \\
\hline Curd: covering by inner & not covered & 4 & Kashi Kunwari, Pusa Himjyoti, Pusa \\
\hline
\end{tabular}




\begin{tabular}{|c|c|c|c|}
\hline Plant descriptors & $\begin{array}{c}\text { Range in } \\
\text { expression }\end{array}$ & $\begin{array}{c}\text { No. of } \\
\text { varieties }\end{array}$ & Example varieties \\
\hline \multirow[t]{3}{*}{ leaves } & & & Deepali, Pusa Meghna \\
\hline & partly covered & 7 & $\begin{array}{l}\text { Kashi Agahani Pusa Paushja, Pusa Sharad, } \\
\text { Pusa Shukti }\end{array}$ \\
\hline & covered & 4 & $\begin{array}{l}\text { PSBK-1, PSB-16, PSBK-25, Pusa Snow } \\
\text { Ball-1 }\end{array}$ \\
\hline \multirow[t]{3}{*}{ Curd: polar diameter } & small $(<15 \mathrm{~cm})$ & 4 & $\begin{array}{l}\text { Pusa Himjyoti, Pusa Deepali, Pusa } \\
\text { Meghna }\end{array}$ \\
\hline & medium $(15-20 \mathrm{~cm})$ & 9 & Kashi Agahani Pusa Paushja, Pusa Sharad \\
\hline & large $(>20 \mathrm{~cm})$ & 2 & Pusa Shukti, PSBK-1 \\
\hline \multirow[t]{3}{*}{$\begin{array}{l}\text { Curd: equatorial } \\
\text { diameter }\end{array}$} & small $(<15 \mathrm{~cm})$ & 4 & $\begin{array}{l}\text { Pusa Himjyoti, Pusa Deepali, Pusa } \\
\text { Meghna }\end{array}$ \\
\hline & medium $(15-20 \mathrm{~cm})$ & 9 & Kashi Agahani Pusa Paushja, Pusa Sharad \\
\hline & large (>20cm) & 2 & Pusa Shukti, PSBK-1 \\
\hline \multirow{3}{*}{$\begin{array}{l}\text { Curd: shape in } \\
\text { longitudinal section }\end{array}$} & circular & 1 & Pusa Himjyoti \\
\hline & broad elliptic & 11 & $\begin{array}{l}\text { Kashi Kunwari, Kashi Agahani Pusa } \\
\text { Paushja, Pusa Sharad, PSBK-25 }\end{array}$ \\
\hline & narrow elliptic & 3 & Pusa Deepali, Pusa Meghna PSB-1 \\
\hline \multirow[t]{3}{*}{ Curd: doming } & weak & 1 & Pusa Meghna \\
\hline & medium & 13 & $\begin{array}{l}\text { Kashi Kunwari, Kashi Agahani, PSBK-25, } \\
\text { Pusa Sharad, Pusa Himjyoti }\end{array}$ \\
\hline & strong & 1 & Pusa Paushja \\
\hline \multirow[t]{3}{*}{ Curd: compactness } & loose & 0 & Nil \\
\hline & medium & 7 & $\begin{array}{l}\text { Pusa Himjyoti, Pusa Deepali, Pusa } \\
\text { Meghna, }\end{array}$ \\
\hline & compact & 8 & $\begin{array}{l}\text { PSBK-25, Pusa Sharad, Pusa Paushja, } \\
\text { Pusa Shukti }\end{array}$ \\
\hline \multirow[t]{4}{*}{ Curd: maturity group } & early & 1 & Pusa Deepali \\
\hline & mid-early & 2 & Kashi Kunwari, Pusa Meghna \\
\hline & mid-late & 9 & $\begin{array}{l}\text { Pusa Paushja, Pusa Shukti ,Pusa Sharad, } \\
\text { Kashi Agahani }\end{array}$ \\
\hline & late & 3 & PSBK-25, PSB-1, Pusa Snowball -1 \\
\hline \multirow[t]{3}{*}{ Flower: colour } & white & 0 & Nil \\
\hline & creamy white & 3 & $\begin{array}{l}\text { Pusa Himjyoti, Pusa Deepali, Pusa } \\
\text { Meghna }\end{array}$ \\
\hline & yellow & 8 & $\begin{array}{l}\text { Pusa Sharad, Kashi Agahani, Pusa } \\
\text { Himjyoti, Kashi Kunwari }\end{array}$ \\
\hline
\end{tabular}

